\title{
Adamantinomatous craniopharyngioma: moving toward targeted therapies
}

\author{
Astrid C. Hengartner, BS, ${ }^{1}$ Eric Prince, BS, ${ }^{1}$ Trinka Vijmasi, MD, ${ }^{1}$ and \\ Todd C. Hankinson, MD, MBA ${ }^{1,2}$ \\ ${ }^{1}$ Pediatric Neurosurgery, Children's Hospital Colorado, University of Colorado School of Medicine; and 2Morgan Adams \\ Foundation Pediatric Brain Tumor Program, Aurora, Colorado
}

\begin{abstract}
The evolving characterization of the biological basis of adamantinomatous craniopharyngioma (ACP) has provided insights critical for novel systemically delivered therapies. While current treatment strategies for ACP are associated with low mortality rates, patients experience severely lowered quality of life due to high recurrence rates and chronic sequelae, presenting a need for novel effective treatment regimens. The identification of various dysregulated pathways that play roles in the pathogenesis of ACP has prompted the investigation of novel treatment options. Aberrations in the CTNNB1 gene lead to the dysregulation of the Wnt pathway and the accumulation of nuclear $\beta$-catenin, which may play a role in tumor invasiveness. While Wnt pathway/ $\beta$-catenin inhibition may be a promising treatment for $A C P$, potential off-target effects have limited its use in current intervention strategies. Promising evidence of the therapeutic potential of cystic proinflammatory mediators and immunosuppressants has been translated into clinical therapies, including interleukin 6 and IDO-1 inhibition. The dysregulation of the pathways of mitogen-activated protein kinase/extracellular signal-regulated kinase (MAPK/ERK), epidermal growth factor receptor (EGFR), and programmed cell death protein 1 and its ligand (PD-1/PD-L1) has led to identification of various therapeutic targets that have shown promise as clinical strategies. The Sonic Hedgehog $(\mathrm{SHH})$ pathway is upregulated in ACP and has been implicated in tumorigenesis and tumor growth; however, inhibition of SHH in murine models decreased survival, limiting its therapeutic application. While further preclinical and clinical data are needed, systemically delivered therapies could delay or replace the need for more aggressive definitive treatments. Ongoing preclinical investigations and clinical trials of these prospective pathways promise to advance treatment approaches aimed to increase patients' quality of life.
\end{abstract}

https://thejns.org/doi/abs/10.3171/2019.10.FOCUS19705

KEYWORDS adamantinomatous craniopharyngioma; childhood craniopharyngioma; targeted therapies; genetically engineered mouse model

A DAMANTINOMATOUS craniopharyngioma (ACP) is a benign tumor that arises from remnants of Rathke's pouch in the sellar/suprasellar region of the brain. This variable heterogeneous neoplasm is characterized by complex epithelial patterns, cystic components, and dystrophic calcium deposits. ACP makes up 6\%-9\% of pediatric brain tumors. ${ }^{51}$ The pathobiology and origins of ACP are incompletely understood, hindering the ability of clinicians to effectively manage these tumors. The current standard treatment for ACP is surgery with or without radiation therapy. Despite radical surgical interventions, the tumor's propensity to infiltrate or damage neighboring tissues such as the hypothalamus, pituitary stalk, and optic chiasm may complicate complete resection or result in severe neuroendocrine damage. Even with complete resection, outcomes are commonly bleak. Due to long-term sequelae, including severe obesity, diabetes insipidus, visual deficits, and hypothalamic syndrome, many patients experience a significantly lower quality of life even after treatment. ${ }^{20,51}$ Recently, an evolving understanding of the biological basis of ACP behavior has enabled the development of new potential treatment options. In this review we discuss current knowledge of molecular characteristics of ACP and their relevance to potential systemically delivered targeted therapies that may improve ACP tumor control and patients' long-term quality of life.

ABBREVIATIONS ACP = adamantinomatous craniopharyngioma; ERK = extracellular signal-regulated kinase; IFN = interferon; IL-6 = interleukin 6; MAPK = mitogenactivated protein kinase; $\mathrm{MEK}=$ mitogen extracellular kinase; $\mathrm{PD}-1=$ programmed cell death protein $1 ; \mathrm{PD}-\mathrm{L} 1=$ programmed cell death protein ligand 1 ; SHH = Sonic Hedgehog; TGF- $\alpha=$ transforming growth factor $-\alpha$. 


\section{The Wnt Pathway and $\beta$-Catenin}

A key pathological feature of ACP is dysregulation of the canonical Wnt/ $\beta$-catenin pathway. The Wnt pathway is responsible for organ formation during embryogenesis and maintenance of adult stem cells. ${ }^{31,37} \beta$-catenin, encoded by the CTNNB1 gene, is among the proteins that play a key role in the Wnt pathway. ${ }^{12} \beta$-catenin has been implicated in development as well as cellular proliferation, migration, and differentiation. ${ }^{11,12}$ To date, the only known recurrent genetic aberration of ACP is mutation of CTNNBI that results in the accumulation of $\beta$-catenin.

Mutations in exon 3 of CTNNB1 have been described in $57 \%-96 \%$ of ACP patients. ${ }^{10,62}$ This mutation modulates the expression profile of $\beta$-catenin by hindering the formation of the $\beta$-catenin destruction complex via alterations of serine and threonine residues at or flanking phosphorylation sites of GSK-3 $\beta$, a key component of the $\beta$-catenin destruction complex. ${ }^{37,61}$ As a result, $\beta$-catenin accumulates in the cytoplasm and eventually translocates to the nucleus, where it interacts with transcription factors such as lymphoid enhancer-binding factor 1/T-cell-specific transcription factor ( $\mathrm{LEF} / \mathrm{TCF})$. This factor promotes expression of the actin bundling protein fascin-1 (fascin) and activation of Wnt, which stimulate cell proliferation and migration. $8,28,29,59$

Nuclear $\beta$-catenin accumulation is found in selective cell cluster whorls, localized predominantly at the tumorbrain barrier (Fig. 1). ${ }^{28}$ These whorls display tumor stem cell-like characteristics, suggesting that infiltrative behavior may be related to activation of the Wnt pathway. ${ }^{31}$ This concept is supported by experiments demonstrating that neoplastic cells with elevated levels of $\beta$-catenin show increased migration capabilities due to increased Wntsignaling activation. ${ }^{28}$ Conversely, inhibition of $\beta$-catenin expression reduces the invasion capacity of ACP tumor cells in culture..$^{28}$

Clinically, Wnt pathway inhibition via reagents such as XNW7201, CGX1321, and RXC004 is being explored for adult non-CNS tumors (clinicaltrials.gov identifiers NCT03901950, NCT02675946, and NCT03447470), but has not yet been studied in children. There are currently no additional preclinical data. While Wnt pathway/ $\beta$ catenin inhibition may become a promising treatment for $\mathrm{ACP}$, there have been concerns that agents targeting this pathway may be associated with significant off-target effects. For these reasons, direct intervention targeting the Wnt pathway/ $\beta$-catenin is not a component of current intervention strategies.

\section{Cyst Fluid and Inflammation}

In addition to the contrast-enhancing solid tumor component, over $90 \%$ of ACPs present with a cystic component. ${ }^{65}$ The presence of cyst fluid raises unique challenges, including the potential for rapid growth that may damage surrounding tissues, increased intracranial pressure, and unpredictable responses to therapies. Intracystic therapies that control cyst expansion may therefore aid in the management of local tumor effects with or without radical surgical intervention.

Intracystic catheter insertion via stereotactic and/or

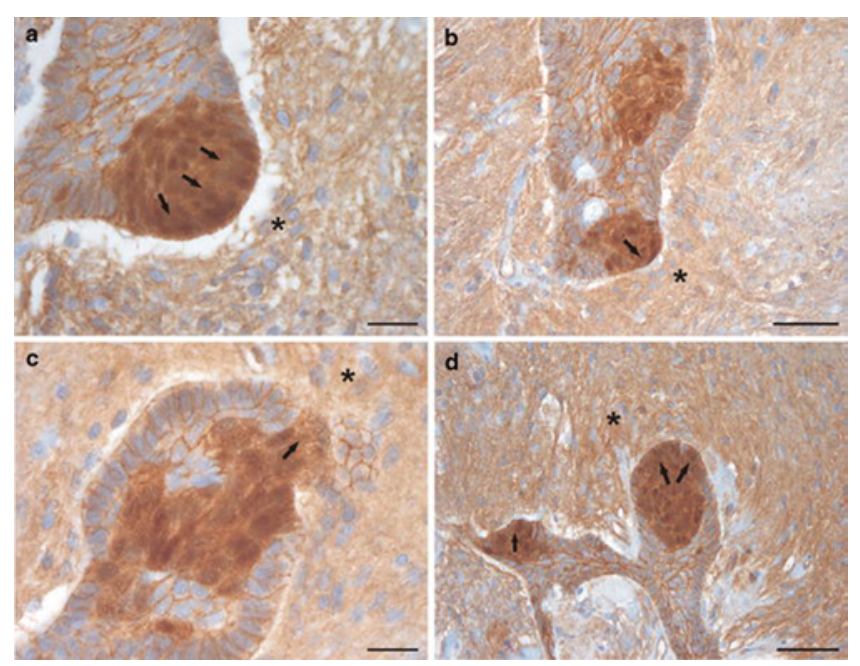

FIG. 1. a-d: In ACP, finger-like protrusions of the tumor into adjacent normal tissue are common (arrows indicate regions of $\beta$-catenin accumulation). Immunohistochemical staining for $\beta$-catenin reveals nuclear and cytoplasmic accumulation of $\beta$-catenin at the interdigitating interface between normal and tumor tissue (asterisks indicate adjacent brain tissue). Bars in panels a and c correspond to $20 \mu \mathrm{m}$ and in b and d to 50 um. Reprinted by permission from Springer Nature. Acta Neuropathol (Berl) 119:631-639; Hölsken A, Buchfelder M, Fahlbusch R, Blümcke I, Buslei R: Tumour cell migration in adamantinomatous craniopharyngiomas is promoted by activated Wnt-signalling, 2010.

endoscopic techniques has been reported as a means to effectively drain cystic tumors..$^{27,35}$ However, intracystic therapies appear to represent a temporary solution, as demonstrated by high rates of recurrence of cystic tumor symptoms within a relatively short period of time, ${ }^{19,53}$ especially as the neurosurgery and neuro-oncology communities increasingly recognize ACP as a chronic disease. As such, current direct intracystic therapies, such as interferon (IFN), bleomycin, and radioisotopes, play a role in ACP control but in most cases are not long-term tumor control solutions.

Intratumoral bleomycin has been widely used as a therapeutic strategy for cystic ACP.,15,26 However, as a neurotoxin, bleomycin is associated with high potential risks, such as hypothalamic injury, seizures, blindness, and fatality. ${ }^{6,42,59}$ In addition to such risks, the short-term tumor control offered by bleomycin limits this chemotherapeutic agent's role in the treatment of ACP.4,65

A safer alternative to bleomycin, intracystic IFN- $\alpha$, has been documented as an effective treatment of ACP in several studies., ${ }^{4,14,34}$ Proteomic analyses of ACP cyst fluid demonstrate elevated levels of the antimicrobial peptides $\alpha$-defensins $1-3$, indicative of an inflammatory response. ${ }^{47,54}$ Patients treated with IFN- $\alpha$ showed decreased cyst fluid concentrations of $\alpha$-defensins and shrinkage of cysts. ${ }^{14,34,47,54}$ The effective cyst fluid control offered by IFN- $\alpha$ may delay inevitable invasive surgical and intracranial radiotherapy treatments for several years. ${ }^{38}$ Such delays may significantly benefit the neural and endocrinal development of young patients. IFN- $\alpha$ effectively reduces cyst fluid volume by activating the Fas apoptotic pathway. ${ }^{34}$ These results suggest a role for inflammatory 

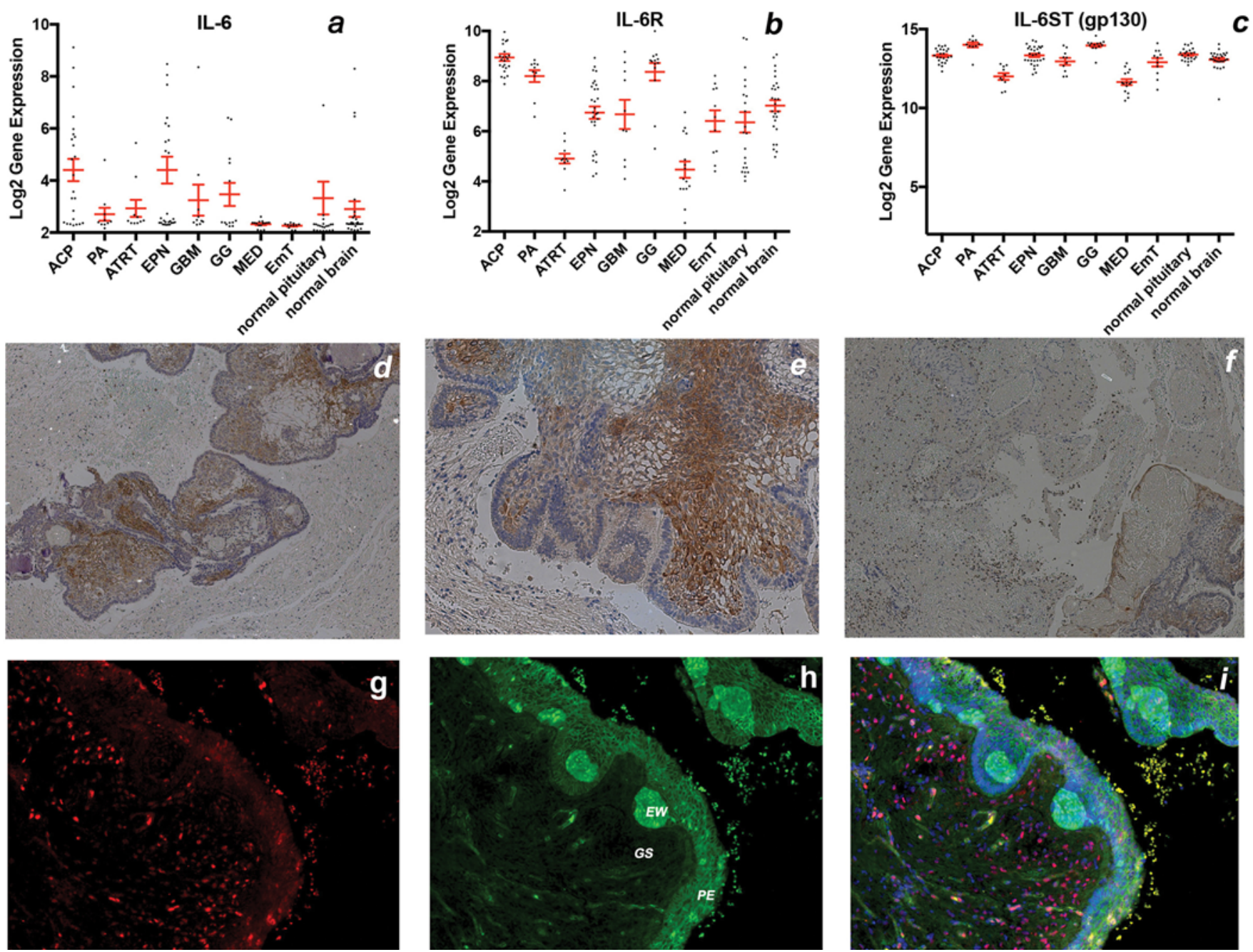

FIG. 2. a-c: Gene expression of IL-6 and IL-6 receptor components in ACP in comparison to normal brain tissue and other brain tumors, including pilocytic astrocytoma (PA), atypical teratoid/rhabdoid tumor (ATRT), ependymoma (EPN), glioblastoma (GBM), ganglioglioma (GG), medulloblastomas (MED), and other embryonal tumors (EmT). d-f: Immunohistochemical staining for IL-6 receptor $\alpha$ in ACP shows strong signals throughout the stellate reticulum but shows only sparse staining in the adjacent epithelial cell regions and in the reactive astrocytic regions. $\mathbf{g}-\mathbf{i}$ : Double immunofluorescence staining for pSTAT3 (red) and $\beta$-catenin (green) in ACP shows positivity in epithelial and surrounding glial compartments. Labels in panel $h$ indicate epithelial whorls (EW), palisading epithelium (PE), and reactive glial supporting tissue (GS). Reproduced from Donson AM, Apps J, Griesinger AM, Amani V, Witt DA, Anderson RCE, et al: Molecular analyses reveal inflammatory mediators in the solid component and cyst fluid of human adamantinomatous craniopharyngioma. J Neuropathol Exp Neurol 76:779-788, 2017. Published by Oxford University Press; (C) 2017 American Association of Neuropathologists, Inc. Reprinted with permission.

pathways and the innate immune response in the development and maintenance of cystic ACP components. While understanding the complete mechanisms and effects of IFN- $\alpha$ requires further investigation, the integration of IFN- $\alpha$ into ACP treatment regimens for cystic tumors may increase the efficacy and lower the morbidity of treatments.

The increased levels of proinflammatory mediators in ACP cyst fluid and solid tissue further support the role of inflammation in ACP pathogenesis, raising the possibility that targeted inflammatory blockade is a strategy that may play a role in therapy. Characterization of cyst fluid and solid tumor tissue has shown elevated concentrations of proinflammatory mediators, including interleukin 6 (IL-
6), IL-8, IL-10, and CXCL1 at protein and mRNA levels compared with concentrations in other pediatric brain tumors and healthy brain tissue (Fig. 2)..$^{19,25,50}$ Cyst fluid characterization has also revealed elevated concentrations of IDO-1, an immunosuppressant, ${ }^{19}$ and the presence of $\beta$-thymosins, peptides with antiapoptotic and antiinflammatory properties. ${ }^{18}$

The translation of these findings through the application of directed antiinflammatory therapies targeting IL-6 has begun to show promise for the treatment of ACP. The human monoclonal antibodies tocilizumab and siltuximab bind to the IL- 6 receptor and IL-6, respectively, hindering IL-6 from exerting its proinflammatory effects. ${ }^{36,45}$ These agents have demonstrated clinical success in the treatment 
of various diseases that are driven in part by dysregulation of IL-6, including systemic juvenile idiopathic arthritis, ${ }^{17,70}$ multicentric Castleman disease, ${ }^{68}$ and CAR (chimeric antigen receptor) T-cell-induced cytokine release syndrome. ${ }^{22}$ These agents are well tolerated in humans, including children, and have regulatory approval in the US and Europe. ${ }^{19,41,70}$ The efficacy of tocilizumab in the treatment of ACP is currently being investigated under a phase 0 clinical trial (NCT03970226) and was recently reported to demonstrate efficacy in 2 patients treated on a compassionate use basis. ${ }^{24} \mathrm{~A}$ multicenter phase II trial of IL-6 inhibition for patients with ACP is also under development.

The clinical success of therapies that target other proinflammatory factors in various tumors may guide other potential therapies for ACP. Antagonists of proinflammatory cytokines such as IL-8 and CXCL1, which have been linked with tumorigenesis and invasive tumor behavior, have shown therapeutic potential in preclinical human cancer models. ${ }^{63,64,66}$ ABX-IL8, an antibody that inhibits the function of IL-8, inhibited tumor growth in various cancers in preclinical studies. ${ }^{32,48}$ However, because of a failure to meet the primary endpoint in a separate psoriasis trial, the effectiveness of ABX-IL8 in clinical settings remains unknown. ${ }^{69}$ IDO-1, an immunosuppressant metabolic enzyme, presents another potential drug target. Clinical trials for the IDO-1 inhibitors epacadostat (INCB024360) and GDC-0919 are currently underway and may provide evidence that the drugs are well tolerated. ${ }^{5,52}$ While the effectiveness of such selective targeting of proinflammatory molecules is yet to be investigated in ACP, such drugs may provide a new approach to the treatment of ACP.

\section{The MAPK/ERK and EGFR Pathways}

Recent findings implicating the mitogen-activated-protein kinase/extracellular signal-regulated kinase (MAPK/ ERK) and epidermal growth factor receptor (EGFR) pathways in the growth and development of ACP have provided further potential avenues for therapeutic intervention. In healthy cells, the MAPK/ERK pathway mediates the intracellular signals transduced from a range of extracellular stimuli and regulates cell proliferation, survival, differentiation, and motility. ${ }^{29}$ Overactivity of the MAPK/ ERK pathway, which occurs in several cancers, plays a role in uncontrolled cancer cell growth, proliferation, and migration. ${ }^{7,46,49}$

The MAPK/ERK pathway is regulated by the upstream activity of EGFR, Ras, Raf, and, most proximally, mitogen extracellular kinase (MEK). Due to evidence of dysregulation of the MAPK/ERK pathway in ACP, ${ }^{3}$ the roles of EGFR, Ras, Raf, and MEK should be explored as potential therapeutic targets.

While overexpression or mutational activation of EGFR has been found in several cancers, ${ }^{23} \mathrm{ACP}$ does not present with mutations or amplifications of the EGFR gene. ${ }^{31}$ However, a study of the ACP transcriptome identified amplified levels of EGFR pathway genes. ${ }^{25}$ Activation of the MAPK/ ERK pathway and EGFR signaling pathways have been shown in $\beta$-catenin aggregating cell clusters at the ACP tumor-brain border, suggesting the role of EGFR in brain infiltration. ${ }^{3,29,31}$ EGFR activity has also been correlated with cell growth and migration by ACP in cell culture models and in vitro. ${ }^{25,29}$ Although they may provide a therapeutic benefit to ACP patients, EGFR antagonists must be further investigated through preclinical and clinical studies before their application in the ACP treatment regimen.

Atypical overexpression of EGFR has been shown to cause hyperactivation of Ras kinase, another upstream activator of the MAPK/ERK pathway. ${ }^{33,44}$ When activated, Ras stimulates transcriptional activity of the gene for transforming growth factor- $\alpha$ (TGF- $\alpha$ ). ${ }^{58}$ TGF- $\alpha$ is a ligand for EGFR, upregulating the activity of EGFR through an autocrine feedback loop without necessarily overactivating the EGFR gene. Upregulation of the expression and secretion of TGF- $\alpha$ has been observed in various Ras- and Raf-transformed cell types. ${ }^{21,60}$ Due to the dysregulation of the MAPK/ERK pathway in various cancers, extensive efforts have been devoted to developing Raf and Ras kinase inhibitors. ${ }^{49}$ As of yet, no clinical trials have explored the effects of Ras or Raf inhibitors on ACP.

MEK inhibition is increasingly being used clinically, specifically for the management of low-grade glial tumors. In the context of leveraging recent knowledge of the MAPK/ERK pathway in ACP, this is also where translation to clinical use has made the greatest progress. Apps and colleagues demonstrated that in explanted human and mouse ACP cultures, the inhibition of the MAPK/ERK pathway via trametinib, an FDA-approved MEK inhibitor, reduced proliferation and increased apoptosis of tumor cells (Fig. 3). ${ }^{3}$ Trametinib has shown promising clinical results in various solid tumors, including in papillary craniopharyngioma, which is characterized by the BRAFv600e mutation rather than the CTNNB1 mutation seen in ACP. ${ }^{9}$ Trametinib is currently being investigated in clinical trials for the treatment of various solid tumors in pediatric patients (NCT02124772). ${ }^{39,58}$ These results suggest that MEK inhibition could provide a clinically viable treatment. Future investigations of the MAPK/ERK pathway could offer promising solutions for the management of $\mathrm{ACP}$, and a multicenter phase II clinical trial is now under development.

\section{The Programmed Cell Death Pathway}

In several cancers, blockade of immune checkpoints has been investigated as a successful antitumor therapy ${ }^{55,56}$ In particular, interruption of the immune checkpoint molecules programmed cell death protein 1 (PD-1) and programmed cell death protein ligand 1 (PD-L1) has suggested a successful antitumor therapeutic option. ${ }^{8,67}$ Recent support for the roles of PD-1 and PD-L1 in ACP provides another new avenue for potential systemic treatment. ${ }^{16}$ Coy and colleagues described consistent and unique localization patterns of upregulated expression of intrinsic PD-1 and PD-L1 in ACP. ${ }^{16}$ Elevated expressions of PD-1 were found only in nuclear $\beta$-catenin-accumulating cell clusters..$^{16}$ In melanoma, PD-1 expression has been linked to tumorigenesis through the downstream activation of MAPK/ERK.$^{40}$ While elevated PD-1 levels in ACP were associated with increased levels of phosphorylated ERK and activation of the downstream MAPK/ERK pathway, investigation of whorled cells exhibiting elevated PD-1 lev- 
Human ACP Ex Vivo

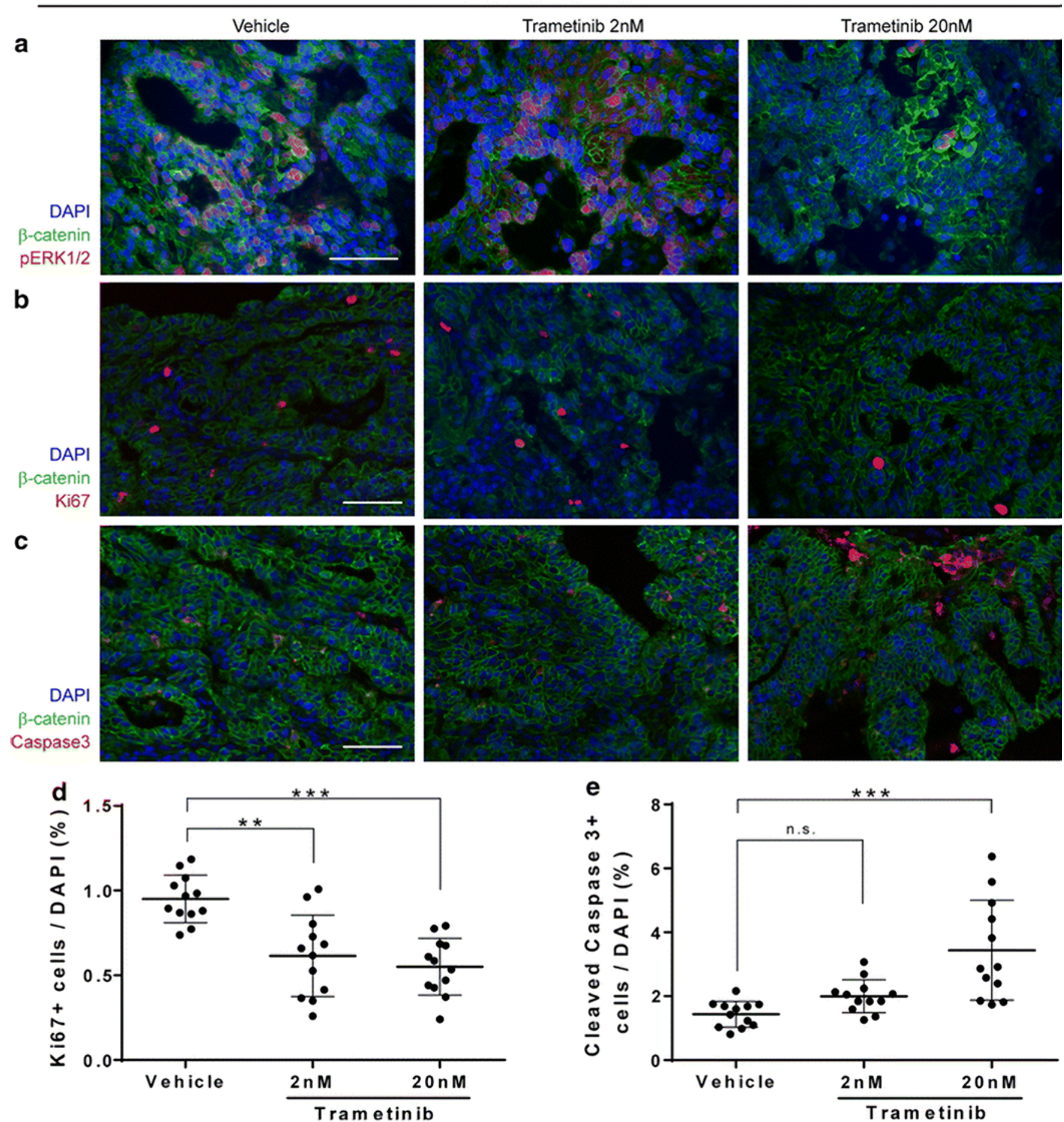

FIG. 3. Inhibition of the MAPK/ERK pathway using trametinib in a human ACP ex vivo model demonstrates decreased proliferation and increased apoptosis of ACP tumor cells. Immunohistochemical staining for $\beta$-catenin, activated pERK1/2, Ki-67, and cleaved caspase-3 showed significant dose-dependent reduction of the proliferative index and an increase in apoptosis in trametinibtreated ACP ex vivo cultures in comparison to vehicle-treated control. Bars $=50 \mu \mathrm{m}$. Reproduced with permission from Apps $\mathrm{JR}$, Carreno G, Gonzalez-Meljem JM, Haston S, Guiho R, Cooper JE, et al: Tumor compartment transcriptomics demonstrates the activation of inflammatory and odontogenic programs in human adamantinomatous craniopharyngioma and identifies the MAPK/ ERK pathway as a novel therapeutic target. Acta Neuropathol (Berl) 135:757-777, 2018. @ 2018 The Authors. CC BY 4.0 (https:/l creativecommons.org/licenses/by/4.0/). 

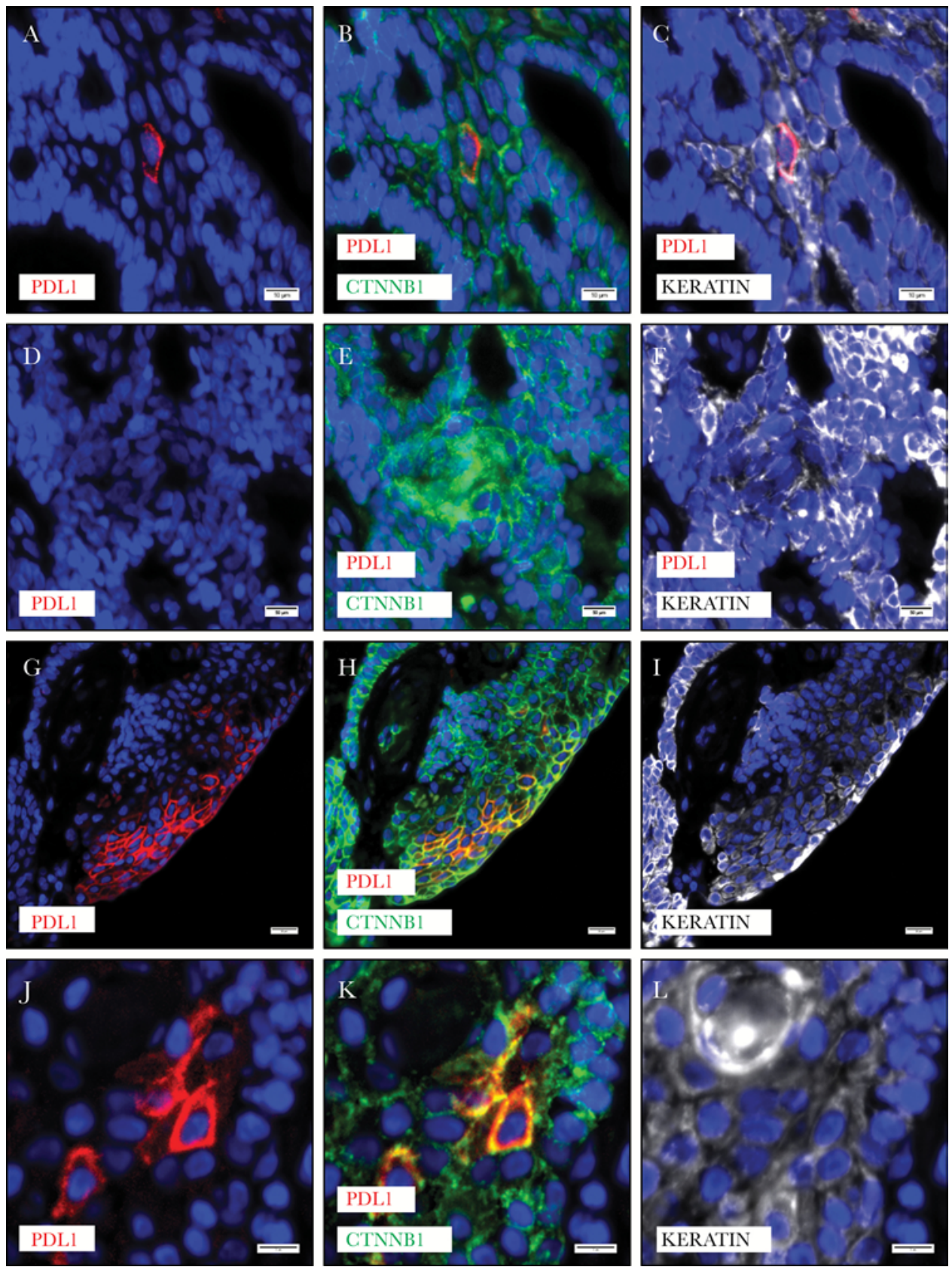

FIG. 4. ACP cells in the basaloid epithelium that express PD-L1 (A) are positive for membranous (inactive) $\beta$-catenin (CTNNB1; B) and keratin (C). Cell cluster whorls of nuclear $\beta$-catenin accumulation do not express PD-L1, but are positive for keratin (D-F). Cells at the cyst lining that show PD-L1 expression are positive for membranous $\beta$-catenin (G-I). Cells that expressed PD-L1 and were near "wet keratin" were epithelial cells positive for keratin and membranous $\beta$-catenin (J-L). Reproduced from Coy $S$, Rashid R, Lin JR, Du Z, Donson AM, Hankinson TC, et al: Multiplexed immunofluorescence reveals potential PD-1/PD-L1 pathway vulnerabilities in craniopharyngioma. Neuro-Oncol 20:1101-1112, 2018. Published by Oxford University Press on behalf of the Society for Neuro-Oncology. @ 2018 The Authors. Reprinted with permission.

els suggested that they are not prolific, which indicates that in ACP, the PD-1 pathway may not be directly involved in tumor cell growth and proliferation. ${ }^{16}$ Nevertheless, the expression of PD-1 in nuclear $\beta$-catenin-accumulating cell clusters, proposed to be tumor stem cell-like regions, ${ }^{31}$ suggests the potential of the PD-1 pathway to serve as a therapeutic target. ${ }^{16}$
PD-L1, on the other hand, was not expressed in $\beta$-catenin-accumulating cell whorls in the work by Coy and colleagues. Rather, elevated levels of PD-L1 were found in a significant number of tumor and immune cells localized at the cyst lining (Fig. 4) ${ }^{16}$ While the mechanism for upregulation of PD-L1 in ACP is incompletely understood, its presence along the cyst lining implies 
some interaction with the highly proinflammatory milieu of ACP cyst fluid. It is possible that PD-L1 pathologically regulates the activity of tumor-associated immune cells. In addition, as PD-L1 elevation correlates with EGFR activation in ACP, ${ }^{16}$ targeting PD-L1 may affect the EGFR and MAPK/ERK pathways, with the potential to inhibit tumor growth.

FDA-approved PD-1 and PD-L1 antagonists that are well tolerated have successfully inhibited growth in various tumors. ${ }^{72}$ Although preliminary data exist for the role of the PD-1/PD-L1 pathway in ACP, additional research is needed to resolve its involvement in tumor growth and to develop targeted antitumor strategies.

\section{The Sonic Hedgehog Pathway}

The Sonic Hedgehog ( $\mathrm{SHH})$ signaling pathway plays a role in the regulation of cell differentiation and proliferation as well as the normal development of organs such as Rathke's pouch. ${ }^{43,57} \mathrm{SHH}$ has been implicated in tumorigenesis and tumor growth in various cancers. ${ }^{53,71}$ In investigations of ACP, SHH upregulation has been described in human and mouse models..$^{2,25,30}$ While the inhibition of the SHH pathway has shown success in the treatment of some cancers, ${ }^{57}$ a recent study by Carreno and colleagues demonstrated that the treatment of ACP with visomodegib, an FDA-approved SHH pathway inhibitor, results in a substantial reduction in median survival in murine models. ${ }^{13}$ This result, combined with evidence that inhibition of the SHH pathway in human ACP leads to increased tumor cell proliferation in explant cultures and patient-derived xenograft models, ${ }^{13}$ precludes consideration of $\mathrm{SHH}$ inhibitors as a viable treatment for ACP at this time.

\section{Conclusions}

Recent advances in our understanding of the biological framework of ACP have greatly improved prospects for effective novel treatments. The identification and exploration of several pathways implicated in the development and growth of ACP provide opportunities to develop new therapeutic strategies that may increase the quality of life of ACP patients. Targeted systemic therapeutic strategies may allow for less aggressive neurosurgical interventions and consequently reduce the morbidity and risks of such treatments. Systemic therapeutic regimens may be particularly beneficial to patients with frequent tumor recurrence and highly infiltrative tumors without the prospect of complete resection. While further research is needed to effectively translate these laboratory findings to clinical settings, ongoing preclinical investigations and clinical trials of these prospective pathways continue to shape and inform the treatment of ACP.

\section{Acknowledgments}

The authors thank Susan Staulcup, MS, for her extensive organizational and administrative support. This work was supported by the Morgan Adams Foundation Pediatric Brain Tumor Program (T.C.H.), the Brain Tumour Charity (GN-000522), and the National Cancer Institute (NCI 1 R03 CA212800 and NCI R03 CA235200). This work has been made possible by the Advanced Treatment for Pediatric Craniopharyngioma (ATPC) Consortium.

\section{References}

1. Alén JF, Boto GR, Lagares A, de la Lama A, Gómez PA, Lobato RD: Intratumoural bleomycin as a treatment for recurrent cystic craniopharyngioma. Case report and review of the literature. Neurocirugia (Astur) 13:479-485, 2002

2. Andoniadou CL, Gaston-Massuet C, Reddy R, Schneider RP, Blasco MA, Le Tissier P, et al: Identification of novel pathways involved in the pathogenesis of human adamantinomatous craniopharyngioma. Acta Neuropathol 124:259-271, 2012

3. Apps JR, Carreno G, Gonzalez-Meljem JM, Haston S, Guiho $\mathrm{R}$, Cooper JE, et al: Tumour compartment transcriptomics demonstrates the activation of inflammatory and odontogenic programmes in human adamantinomatous craniopharyngioma and identifies the MAPK/ERK pathway as a novel therapeutic target. Acta Neuropathol 135:757-777, 2018

4. Bartels U, Laperriere N, Bouffet E, Drake J: Intracystic therapies for cystic craniopharyngioma in childhood. Front Endocrinol (Lausanne) 3:39, 2012

5. Beatty GL, O’Dwyer PJ, Clark J, Shi JG, Bowman KJ, Scherle PA, et al: First-in-human phase I study of the oral inhibitor of indoleamine 2,3-dioxygenase-1 epacadostat (INCB024360) in patients with advanced solid malignancies. Clin Cancer Res 23:3269-3276, 2017

6. Belen D, Er U, Yigitkanli K, Bolay H: Delayed neurotoxic complication of intracavitary bleomycin therapy for craniopharyngioma in a child who had previously undergone radiosurgery. Case report. J Neurosurg 106 (5 Suppl):391-393, 2007

7. Blaj C, Schmidt EM, Lamprecht S, Hermeking H, Jung A, Kirchner T, et al: Oncogenic effects of high MAPK activity in colorectal cancer mark progenitor cells and persist irrespective of RAS mutations. Cancer Res 77:1763-1774, 2017

8. Brahmer JR, Tykodi SS, Chow LQM, Hwu WJ, Topalian SL, Hwu P, et al: Safety and activity of anti-PD-L1 antibody in patients with advanced cancer. N Engl J Med 366:24552465,2012

9. Brastianos PK, Shankar GM, Gill CM, Taylor-Weiner A, Nayyar N, Panka DJ, et al: Dramatic response of BRAF V600E mutant papillary craniopharyngioma to targeted therapy. J Natl Cancer Inst 108:djv310, 2015

10. Brastianos PK, Taylor-Weiner A, Manley PE, Jones RT, DiasSantagata D, Thorner AR, et al: Exome sequencing identifies BRAF mutations in papillary craniopharyngiomas. Nat Genet 46:161-165, 2014

11. Campanini ML, Colli LM, Paixao BMC, Cabral TPF, Amaral FC, Machado HR, et al: CTNNB1 gene mutations, pituitary transcription factors, and MicroRNA expression involvement in the pathogenesis of adamantinomatous craniopharyngiomas. Horm Cancer 1:187-196, 2010

12. Cani CMG, Matushita H, Carvalho LRS, Soares IC, Brito LP, Almeida MQ, et al: PROP1 and CTNNB1 expression in adamantinomatous craniopharyngiomas with or without $\beta$-catenin mutations. Clinics (São Paulo) 66:1849-1854, 2011

13. Carreno G, Boult JKR, Apps JR, Gonzalez-Meljem JM, Haston S, Guiho R, et al: SHH pathway inhibition is protumourigenic in adamantinomatous craniopharyngioma. Endocr Relat Cancer 26:355-366, 2019

14. Cavalheiro S, Dastoli PA, Silva NS, Toledo S, Lederman H, da Silva MC: Use of interferon alpha in intratumoral chemotherapy for cystic craniopharyngioma. Childs Nerv Syst 21:719-724, 2005

15. Cavalheiro S, Sparapani FV, Franco JOB, da Silva MC, Braga FM: Use of bleomycin in intratumoral chemotherapy for cystic craniopharyngioma. Case report. J Neurosurg 84:124-126, 1996

16. Coy S, Rashid R, Lin JR, Du Z, Donson AM, Hankinson TC, et al: Multiplexed immunofluorescence reveals potential 
PD-1/PD-L1 pathway vulnerabilities in craniopharyngioma. Neuro Oncol 20:1101-1112, 2018

17. De Benedetti F, Brunner HI, Ruperto N, Kenwright A, Wright S, Calvo I, et al: Randomized trial of tocilizumab in systemic juvenile idiopathic arthritis. N Engl J Med 367:2385-2395, 2012

18. Desiderio C, Martelli C, Rossetti DV, Di Rocco C, D’Angelo L, Caldarelli M, et al: Identification of thymosins $\beta 4$ and $\beta$ 10 in paediatric craniopharyngioma cystic fluid. Childs Nerv Syst 29:951-960, 2013

19. Donson AM, Apps J, Griesinger AM, Amani V, Witt DA, Anderson RCE, et al: Molecular analyses reveal inflammatory mediators in the solid component and cyst fluid of human adamantinomatous craniopharyngioma. J Neuropathol Exp Neurol 76:779-788, 2017

20. Eveslage M, Calaminus G, Warmuth-Metz M, Kortmann RD, Pohl F, Timmermann B, et al: The postoperative quality of life in children and adolescents with craniopharyngioma. Results of a prospective multicenter study. Dtsch Arztebl Int 116:321-328, 2019

21. Gangarosa LM, Sizemore N, Graves-Deal R, Oldham SM, Der CJ, Coffey RJ: A raf-independent epidermal growth factor receptor autocrine loop is necessary for Ras transformation of rat intestinal epithelial cells. J Biol Chem 272:1892618931,1997

22. Giavridis T, van der Stegen SJC, Eyquem J, Hamieh M, Piersigilli A, Sadelain M: CAR T cell-induced cytokine release syndrome is mediated by macrophages and abated by IL-1 blockade. Nat Med 24:731-738, 2018

23. Grandis JR, Sok JC: Signaling through the epidermal growth factor receptor during the development of malignancy. Pharmacol Ther 102:37-46, 2004

24. Grob S, Mirsky DM, Donson AM, Dahl N, Foreman NK, Hoffman LM, et al: Targeting IL-6 is a potential treatment for primary cystic craniopharyngioma. Front Oncol 9:791, 2019

25. Gump JM, Donson AM, Birks DK, Amani VM, Rao KK, Griesinger AM, et al: Identification of targets for rational pharmacological therapy in childhood craniopharyngioma. Acta Neuropathol Commun 3:30, 2015

26. Hader WJ, Steinbok P, Hukin J, Fryer C: Intratumoral therapy with bleomycin for cystic craniopharyngiomas in children. Pediatr Neurosurg 33:211-218, 2000

27. Hellwig D, Bauer BL, List-Hellwig E: Stereotactic endoscopic interventions in cystic brain lesions in Meyerson BA, Ostertag C (eds): Advances in Stereotactic and Functional Neurosurgery 11. Vienna: Springer, 1995, Vol 64, pp 59-63

28. Hölsken A, Buchfelder M, Fahlbusch R, Blümcke I, Buslei R: Tumour cell migration in adamantinomatous craniopharyngiomas is promoted by activated Wnt-signalling. Acta Neuropathol 119:631-639, 2010

29. Hölsken A, Gebhardt M, Buchfelder M, Fahlbusch R, Blümcke I, Buslei R: EGFR signaling regulates tumor cell migration in craniopharyngiomas. Clin Cancer Res 17:4367-4377, 2011

30. Hölsken A, Sill M, Merkle J, Schweizer L, Buchfelder M, Flitsch J, et al: Adamantinomatous and papillary craniopharyngiomas are characterized by distinct epigenomic as well as mutational and transcriptomic profiles. Acta Neuropathol Commun 4:20, 2016

31. Hölsken A, Stache C, Schlaffer SM, Flitsch J, Fahlbusch R, Buchfelder M, et al: Adamantinomatous craniopharyngiomas express tumor stem cell markers in cells with activated Wnt signaling: further evidence for the existence of a tumor stem cell niche? Pituitary 17:546-556, 2014

32. Huang S, Mills L, Mian B, Tellez C, McCarty M, Yang XD, et al: Fully humanized neutralizing antibodies to interleukin-8 (ABX-IL8) inhibit angiogenesis, tumor growth, and metastasis of human melanoma. Am J Pathol 161:125-134, 2002
33. Hynes NE, Lane HA: ERBB receptors and cancer: the complexity of targeted inhibitors. Nat Rev Cancer 5:341-354, 2005

34. Ierardi DF, Fernandes MJS, Silva IR, Thomazini-Gouveia J, Silva NS, Dastoli P, et al: Apoptosis in alpha interferon (IFN- $\alpha$ ) intratumoral chemotherapy for cystic craniopharyngiomas. Childs Nerv Syst 23:1041-1046, 2007

35. Joki T, Oi S, Babapour B, Kaito N, Ohashi K, Ebara M, et al: Neuroendoscopic placement of Ommaya reservoir into a cystic craniopharyngioma. Childs Nerv Syst 18:629-633, 2002

36. Jones G, Sebba A, Gu J, Lowenstein MB, Calvo A, GomezReino JJ, et al: Comparison of tocilizumab monotherapy versus methotrexate monotherapy in patients with moderate to severe rheumatoid arthritis: the AMBITION study. Ann Rheum Dis 69:88-96, 2010

37. Kato K, Nakatani Y, Kanno H, Inayama Y, Ijiri R, Nagahara N, et al: Possible linkage between specific histological structures and aberrant reactivation of the Wnt pathway in adamantinomatous craniopharyngioma. J Pathol 203:814-821, 2004

38. Kilday JP, Caldarelli M, Massimi L, Chen RHH, Lee YY, Liang ML, et al: Intracystic interferon-alpha in pediatric craniopharyngioma patients: an international multicenter assessment on behalf of SIOPE and ISPN. Neuro Oncol 19:1398-1407, 2017

39. Kinsler VA, O'Hare P, Jacques T, Hargrave D, Slater O: MEK inhibition appears to improve symptom control in primary NRAS-driven CNS melanoma in children. Br J Cancer 116:990-993, 2017

40. Kleffel S, Posch C, Barthel SR, Mueller H, Schlapbach C, Guenova E, et al: Melanoma cell-intrinsic PD-1 receptor functions promote tumor growth. Cell 162:1242-1256, 2015

41. Kurzrock R, Voorhees PM, Casper C, Furman RR, Fayad L, Lonial S, et al: A phase I, open-label study of siltuximab, an anti-IL-6 monoclonal antibody, in patients with B-cell non-Hodgkin lymphoma, multiple myeloma, or Castleman disease. Clin Cancer Res 19:3659-3670, 2013

42. Lafay-Cousin L, Bartels U, Raybaud C, Kulkarni AV, Guger $\mathrm{S}$, Huang A, et al: Neuroradiological findings of bleomycin leakage in cystic craniopharyngioma. Report of three cases. $\mathbf{J}$ Neurosurg 107 (4 Suppl):318-323, 2007

43. Larkin SJ, Ansorge O: Pathology and pathogenesis of craniopharyngiomas. Pituitary 16:9-17, 2013

44. Lynch TJ, Bell DW, Sordella R, Gurubhagavatula S, Okimoto RA, Brannigan BW, et al: Activating mutations in the epidermal growth factor receptor underlying responsiveness of non-small-cell lung cancer to gefitinib. N Engl J Med 350:2129-2139, 2004

45. Markham A, Patel T: Siltuximab: first global approval. Drugs 74:1147-1152, 2014

46. Martinelli E, Morgillo F, Troiani T, Ciardiello F: Cancer resistance to therapies against the EGFR-RAS-RAF pathway: The role of MEK. Cancer Treat Rev 53:61-69, 2017

47. Massimi L, Martelli C, Caldarelli M, Castagnola M, Desiderio C: Proteomics in pediatric cystic craniopharyngioma. Brain Pathol 27:370-376, 2017

48. Mian BM, Dinney CPN, Bermejo CE, Sweeney P, Tellez C, Yang XD, et al: Fully human anti-interleukin 8 antibody inhibits tumor growth in orthotopic bladder cancer xenografts via down-regulation of matrix metalloproteases and nuclear factor- $\kappa$ B. Clin Cancer Res 9:3167-3175, 2003

49. Montagut C, Settleman J: Targeting the RAF-MEK-ERK pathway in cancer therapy. Cancer Lett 283:125-134, 2009

50. Mori M, Takeshima H, Kuratsu J: Expression of interleukin-6 in human craniopharyngiomas: a possible inducer of tumorassociated inflammation. Int J Mol Med 14:505-509, 2004

51. Müller HL, Bruhnken G, Emser A, Faldum A, Etavard-Gorris $\mathrm{N}$, Gebhardt $\mathrm{U}$, et al: Longitudinal study on quality of life in 102 survivors of childhood craniopharyngioma. Childs Nerv Syst 21:975-980, 2005 
52. Nayak-Kapoor A, Hao Z, Sadek R, Dobbins R, Marshall L, Vahanian NN, et al: Phase Ia study of the indoleamine 2,3-dioxygenase 1 (IDO1) inhibitor navoximod (GDC-0919) in patients with recurrent advanced solid tumors. J Immunother Cancer 6:61, 2018

53. Park YS, Chang JH, Park YG, Kim DS: Recurrence rates after neuroendoscopic fenestration and Gamma Knife surgery in comparison with subtotal resection and Gamma Knife surgery for the treatment of cystic craniopharyngiomas. J Neurosurg 114:1360-1368, 2011

54. Pettorini BL, Inzitari R, Massimi L, Tamburrini G, Caldarelli M, Fanali C, et al: The role of inflammation in the genesis of the cystic component of craniopharyngiomas. Childs Nerv Syst 26:1779-1784, 2010

55. Postow MA, Callahan MK, Wolchok JD: Immune checkpoint blockade in cancer therapy. J Clin Oncol 33:1974-1982, 2015

56. Ribas A, Wolchok JD: Cancer immunotherapy using checkpoint blockade. Science 359:1350-1355, 2018

57. Rimkus TK, Carpenter RL, Qasem S, Chan M, Lo HW: Targeting the sonic hedgehog signaling pathway: review of smoothened and GLI inhibitors. Cancers (Basel) 8:22, 2016

58. Roberts PJ, Der CJ: Targeting the Raf-MEK-ERK mitogenactivated protein kinase cascade for the treatment of cancer. Oncogene 26:3291-3310, 2007

59. Savas A, Erdem A, Tun K, Kanpolat Y: Fatal toxic effect of bleomycin on brain tissue after intracystic chemotherapy for a craniopharyngioma: case report. Neurosurgery 46:213217,2000

60. Schulze A, Lehmann K, Jefferies HBJ, McMahon M, Downward J: Analysis of the transcriptional program induced by Raf in epithelial cells. Genes Dev 15:981-994, 2001

61. Sekine S, Shibata T, Kokubu A, Morishita Y, Noguchi M, Nakanishi Y, et al: Craniopharyngiomas of adamantinomatous type harbor $\beta$-catenin gene mutations. Am J Pathol 161:1997-2001, 2002

62. Semba S, Han SY, Ikeda H, Horii A: Frequent nuclear accumulation of beta-catenin in pituitary adenoma. Cancer 91:42-48, 2001

63. Shiau MY, Fan LC, Yang SC, Tsao CH, Lee H, Cheng YW, et al: Human papillomavirus up-regulates MMP-2 and MMP-9 expression and activity by inducing interleukin-8 in lung adenocarcinomas. PLoS One 8: 54423, 2013

64. Singh S, Sadanandam A, Nannuru KC, Varney ML, MayerEzell R, Bond R, et al: Small-molecule antagonists for CXCR2 and CXCR1 inhibit human melanoma growth by decreasing tumor cell proliferation, survival, and angiogenesis. Clin Cancer Res 15:2380-2386, 2009

65. Steinbok P, Hukin J: Intracystic treatments for craniopharyngioma. Neurosurg Focus 28(4):E13, 2010
66. Todd CM, Salter BM, Murphy DM, Watson RM, Howie KJ, Milot J, et al: The effects of a CXCR1/CXCR2 antagonist on neutrophil migration in mild atopic asthmatic subjects. Pulm Pharmacol Ther 41:34-39, 2016

67. Topalian SL, Hodi FS, Brahmer JR, Gettinger SN, Smith DC, McDermott DF, et al: Safety, activity, and immune correlates of anti-PD-1 antibody in cancer. N Engl J Med 366:24432454,2012

68. van Rhee F, Wong RS, Munshi N, Rossi JF, Ke XY, Fosså A, et al: Siltuximab for multicentric Castleman's disease: a randomised, double-blind, placebo-controlled trial. Lancet Oncol 15:966-974, 2014

69. Yan L, Anderson GM, DeWitte M, Nakada MT: Therapeutic potential of cytokine and chemokine antagonists in cancer therapy. Eur J Cancer 42:793-802, 2006

70. Yokota S, Imagawa T, Mori M, Miyamae T, Aihara Y, Takei $\mathrm{S}$, et al: Efficacy and safety of tocilizumab in patients with systemic-onset juvenile idiopathic arthritis: a randomised, double-blind, placebo-controlled, withdrawal phase III trial. Lancet 371:998-1006, 2008

71. Yoo YA, Kang MH, Lee HJ, Kim BH, Park JK, Kim HK, et al: Sonic hedgehog pathway promotes metastasis and lymphangiogenesis via activation of Akt, EMT, and MMP-9 pathway in gastric cancer. Cancer Res 71:7061-7070, 2011

72. Zhan MM, Hu XQ, Liu XX, Ruan BF, Xu J, Liao C: From monoclonal antibodies to small molecules: the development of inhibitors targeting the PD-1/PD-L1 pathway. Drug Discov Today 21:1027-1036, 2016

\section{Disclosures}

The authors report no conflict of interest concerning the materials or methods used in this study or the findings specified in this paper.

\section{Author Contributions}

Conception and design: Hankinson, Hengartner. Acquisition of data: all authors. Drafting the article: Hengartner. Critically revising the article: Hankinson, Hengartner. Reviewed submitted version of manuscript: all authors. Study supervision: Hankinson.

\section{Correspondence}

Todd C. Hankinson: Children's Hospital Colorado and University of Colorado School of Medicine, Aurora, CO. todd.hankinson@ childrenscolorado.org. 